\title{
Longitudinal changes of body mass index, spirometry and diffusion in a general population
}

\author{
M. Bottai*, F. Pistelli", F. Di Pede ${ }^{\#}$, L. Carrozzi ${ }^{\#}$, S. Baldacci ${ }^{\top}$, G. Matteelli" ${ }^{\#}$ A. Scognamiglio", \\ G. Viegi
}

Longitudinal changes of body mass index, spirometry and diffusion in a general population. M. Bottai, F. Pistelli, F. Di Pede, L. Carrozzi, S. Baldacci, G. Matteelli, A. Scognamiglio, G. Viegi. (C) ERS Journals Ltd 2002.

ABSTRACT: The aim of this study was to evaluate the effects of body mass index (BMI) changes over an 8-yr follow-up, on longitudinal changes of vital capacity (VC), forced vital capacity (FVC), forced expiratory volume in one second (FEV1), and carbon monoxide diffusing capacity of the lung $(D \mathrm{~L}, \mathrm{CO})$ indices in a general population sample of North Italy.

To avoid including weight changes possibly related to physical growth, only the 1,426 adults ( $>24$ yrs, $46 \%$ males) with complete follow-up were selected. Median linear regression models were applied to estimate the medians of change (computed as followup minus baseline values) of $\mathrm{VC}, \mathrm{FVC}, \mathrm{FEV} 1$ and $\mathrm{DL}, \mathrm{CO}$ indices, as functions of changes of BMI over the follow-up period, separately by sex, after considering several potential confounders and effect modifiers.

The extent of lung function loss tended to be higher among those who, at baseline, reported greater BMI values. Males experienced larger losses than females (20 and $16 \mathrm{~mL}$ FEV1 median reduction for a BMI unit increase in males and females, respectively). Conversely, longitudinal changes of BMI caused a slight and nonsignificant increase in $D L, C O$ values in both sexes.

Over an 8-yr follow-up, the detrimental effect of gaining weight might be reversible for many adults as most of those who reduced their body mass index values also increased their lung function. Overweight patients with ventilatory impairment should be routinely encouraged to lose weight for improving their lung function. Eur Respir J 2002; 20: 665-673.

\begin{abstract}
*CNUCE Institute of the National Research Council (CNR), ${ }^{\#}$ Cardiac and Thoracic Dept, University and Hospital of Pisa and Institute of Clinical Physiology of the National Research Council (CNR), Pisa, Italy.
\end{abstract}

Correspondence: M. Bottai, Istituto CNUCE, National Research Council of Italy, Via Morizzi 1, 56124 Pisa, Italy.

Fax: 39 0503138091/8092

E-mail: matteo.bottai@cnuce.cnr.it

Keywords: Body mass index, diffusing capacity, forced expiratory volume, spirometry, vital capacity

Received: August 92001

Accepted after revision: January 252002

This study was supported in part by the National Research Council, targeted project "Prevention and Control of Disease Factors, SP2, contract no. 91.00171.PF41"; a grant from the Italian Electric Power Authority (ENEL) and the CNR-ENEL project "Interactions of the Energy System with Human Health Environment", Rome, Italy; by contract no. BMH1-CT920849 (BIOMED1) between the European Economic Community and the University of Pisa, Italy; by educational grants from SmithKline Beecham Pharmaceuticals, Collegeville, PA, USA (1999-2000), and from GlaxoSmithKline, London, UK (2001).
The body mass index (BMI), body weight $(\mathrm{kg})$ to squared height $(\mathrm{m})$ ratio, is a well known index that is receiving increasing attention to evaluate the effects of overall obesity on ventilatory function.

Besides age and height, BMI has recently been considered as an additional independent variable in models for deriving spirometric prediction equations $[1,2]$. In particular, the present authors have previously observed that BMI improved the precision of predictions for both volumes and flows, regardless of sex [2].

Furthermore, BMI or body weight gains have been shown to be related to longitudinal decline of forced expiratory volume in one second (FEV1) and forced vital capacity (FVC) in adults, both in occupational cohorts [3, 4] and in general population samples [5-7].
This effect of BMI on lung function has been shown to be independent of age $[4,5]$. In studies with both males and females, significantly higher effects have been found in males [5-7].

Little is known about the effect of longitudinal changes of BMI on variations of the carbon monoxide diffusing capacity of the lung $(D \mathrm{~L}, \mathrm{CO})$ in large general population samples. Body weight, but not BMI, change was included among predictors of longitudinal change of $D \mathrm{~L}, \mathrm{CO}$ in adults from the Tucson Epidemiological Study of Obstructive Lung Disease, although its effect was not specifically addressed [8]. By applying a statistical model analogous to that applied in the above mentioned paper, the present authors have previously found that weight at baseline and change in weight were significant predictors of $D \mathrm{~L}, \mathrm{CO}$ 
longitudinal increases over an 8-yr period, both in adult males and females from the Po river delta prospective epidemiological study in Italy [9]. With regard to clinical studies, large BMI values have been shown to be an independent determinant of increased diffusion indexes in groups of patients with chronic obstructive pulmonary disease (COPD) [10] and obstructive sleep-apnoea [11]. In a small study on massively obese but otherwise normal, nonsmoking, young adults, the single-breath $D$ L,CO increased with the degree of obesity [12].

The aim of this study was to evaluate the effects of changes of BMI, over an 8-yr follow-up, on longitudinal changes of slow vital capacity (VC), FVC, FEV1, and DL,CO in a general population sample of North Italy.

\section{Methods}

\section{Po river delta study}

The Po river delta prospective epidemiological study was conducted on the general population of a rural area in northern Italy (near Venice) to evaluate the natural history of COPD and to assess the possible health effects of air pollution caused by a large thermoelectric power plant in a previously unpolluted area. The baseline survey was carried out in $1980-1982$ on 3,284 subjects, of whom $2,136(65 \%)$ were followed-up in 1988-1991, to whom 705 new individuals were added [13]. Previous publications have described in detail the characteristics of the sample [14], the questionnaire adopted [15] (the National Research Council of Italy questionnaire on respiratory symptoms, diseases and risk factors, a modified version of the National Heart, Lung and Blood Institute questionnaire), the prevalence rates of respiratory symptoms and diseases $[15,16]$, the effects of risk factors for COPD [17, 18], the lung function test protocols and reference equations $[2,19,20]$.

\section{Selection of subjects}

To evaluate the effects of weight changes over time, the 2,136 subjects with complete questionnaire followup were considered. To avoid including weight changes that may have been related to physical growth, the 1,426 adults $>24$ yrs of age were selected. Both baseline and follow-up measures were provided by 1,201 subjects for the VC manoeuvre, 1,131 subjects for the FVC, and 844 subjects for the $D$ L,CO. Twenty five yrs was chosen as the cut-off value, as it appeared to be the age beyond which all lung function and diffusing capacity indexes considered were decreasing $[2,19]$.

\section{Lung function measurements}

In both surveys, a computerised pneumotachograph (Fleish No.3) (Pulmonary System 47804/S, Hewlett-Packard, Waltham, Massachusetts, USA) was used for measuring volumes. The pneumotachograph was heated at $37^{\circ} \mathrm{C}$, and volumes reported in $\mathrm{L}$ at body temperature and ambient pressure and saturated with water vapour (BTPS). Volume calibration was performed daily using standard syringe $(3 \mathrm{~L})$. The protocol for lung function measurements fulfilled the American Thoracic Society (ATS) recommendations [21], with the exception of the criterion for the end-point of the FVC manoeuvre [22]. At least two trials were repeated to obtain a satisfactory VC value. The highest VC was used for statistical analyses. Up to eight FVC manoeuvres were performed to obtain at least three acceptable trials. To assure reproducibility, the two largest FVC and FEV1 values from acceptable trials had to be within $5 \%$ of each other. The largest FVC and FEV1 values were selected, regardless of the manoeuvre.

The single-breath $D$ L,CO was computed using the method of OGILviE et al. [23], considering the inspired volume at dried ambient temperature and pressure (ATPD). In order to express DL,CO in $\mathrm{mL} \cdot \mathrm{min}^{-1} \cdot \mathrm{mmHg}^{-1}$ volume of gas at standard temperature and pressure that contains no water vapour (STPD), a correction to STPD was performed. Inspired volume of $D \mathrm{~L}, \mathrm{CO}$ had to be $\geqslant 85 \%$ of $\mathrm{VC}$ in order to be acceptable [19]. Breath holding time was computed from the moment when one half of the volume was inspired to the moment when dead space washout was completed and collection of alveolar gas was started, according to ATS recommendations [21]. $\mathrm{Up}$ to four trials were performed to obtain two acceptable manoeuvres; the highest $D \mathrm{~L}, \mathrm{CO}$ value was used in the analyses [19]. Haemoglobin correction was not performed, as collection of blood sample was not included in the study protocol. The carbon monoxide transfer coefficient $(K \mathrm{CO})$ was calculated as the ratio between $D$ L,CO and the alveolar volume $(V \mathrm{~A})$.

\section{Risk factors}

The BMI was computed as the ratio between body weight $(\mathrm{kg})$ and squared height $(\mathrm{m})$. Height and weight were measured in the standing position without shoes in subjects wearing clothes. Age at last birthday was recorded at the baseline survey. Smoking longitudinal categories were defined as "persistent smokers" (those who were smokers at both baseline and follow-up), "never smokers" (those who were never smokers at both baseline and follow-up), "beginners" (those who were never smokers at baseline and smokers at follow-up), "quitters" (those who were smokers at baseline and exsmokers at follow-up), "exsmokers" (those who had quit before the baseline survey), and "other smokers" (the remaining individuals i.e. those who started and quit between the two surveys), based on the smoking status at baseline and follow-up. Socioeconomic status was coded as "low", "medium", and "high" breaking down the sample on the basis of two characteristics: occupation and crowding index (number of house mates to number of rooms ratio). The following factors were measured at baseline and coded as binary variables: occupational exposure (defined as exposure/no exposure to 
any of a list of eighteen noxious agents (dusts, chemicals, and gases) in any of the places the subject had ever worked), physician-confirmed asthma, physicianconfirmed chronic bronchitis and/or physician-confirmed emphysema.

\section{Longitudinal changes of the variables}

All the subjects included in the analysis had complete follow-up, that is they had both baseline and follow-up observations. Thus, longitudinal changes within each subject for all the variables considered in the analysis could be computed. For example, dVC was defined as VC value at follow-up subtracted by VC value at baseline. So defined, dVC assumed positive values when $\mathrm{VC}$ increased over the followup time, and negative values when $\mathrm{VC}$ decreased. Accordingly, dFVC, dFEV1, dFEV1/VC, dFEV1/ FVC, $\mathrm{d} D \mathrm{~L}, \mathrm{CO}, \mathrm{d} K \mathrm{CO}$ and $\mathrm{dBMI}$, were also defined.

\section{Statistical analyses}

Robust methods as percentiles and median regressions were applied. Medians, along with 5th and 95th percentiles, were calculated for the baseline and follow-up samples' characteristics and for their longitudinal changes.

Median linear regression models were applied to estimate the medians of dVC, dFVC, dFEV1, dFEV1/ $\mathrm{VC}, \mathrm{dFEV} 1 / \mathrm{FVC}, \mathrm{d} D \mathrm{~L}, \mathrm{CO}$ and $\mathrm{d} K \mathrm{KO}$ as functions of dBMI, separately by sex. Median regression techniques provide answers similar to the least squares regression when the data are linear with normally distributed errors, but differ significantly from the least squares fit when the errors do not satisfy the normality conditions or when the data contain significant outliers [24]. In particular, for any given set of covariates' values, it allows the median instead of the mean lung function changes to be estimated (medians are less sensitive to outlying values than means). In the present sample, few unusually large weight gains or losses that were physically acceptable yet possibly due to measurement error were observed. Unusually large observations were not allowed to influence the analyses by regressing the covariates on the median instead of the mean. In the Appendix section, the authors present a more detailed description of median regression and an example that illustrates its features.

Several risk factors were included as independent variables: BMI, height, weight, age, socioeconomic status, occupational exposure, physician-confirmed chronic bronchitis and/or physician-confirmed emphysema, and physician-confirmed asthma all recorded at baseline, smoking longitudinal habits, and length of follow-up. Age at baseline, whose removal out of the models provoked a change in the other coefficients' estimates $>10 \%$, was considered confounder and kept in the final models. The p-values were calculated by Wald test except when otherwise stated. Pairwise interactions were not statistically significant except for the one between BMI at baseline and $\mathrm{dBMI}$ in the final model for dVC.

\section{Results}

Baseline and follow-up samples characteristics were compared and the results are shown, separately by sex, in tables 1 and 2. Medians, 5th and 95th percentiles were computed to describe anthropometric measures and respiratory function. Age variations approximately corresponded to the lengths of followup time. Forty-two per cent of subjects were interviewed 8 yrs apart and over $90 \%$ between 7 and 9 yrs apart. Lung function indexes showed negative variations in the overall medians mainly due to aging. No major differences were observed between males and females: variations over time were almost identical, as well as baseline and follow-up values of age and BMI; baseline and follow-up values of weight, height, and lung function measurements were less in females than in males, as expected.

Among the variables considered, only age and FEV1 evaluated at baseline were significantly different $(p<0.05$ by Wilcoxon rank-sum test) between those who had complete longitudinal data and those who had not (43 versus 46 yrs mean age, and 3.06 versus $2.93 \mathrm{~L}$ mean FEV1).

It was observed that most of those who actually lost weight improved their lung function and those who gained weight reduced their lung function. In the sample, as shown in table 3 , there seemed to be a linear relationship in the trend by which the lung

Table 1. - Anthropometric variables at baseline and follow-up and their changes, separately by sex

\begin{tabular}{lccc}
\hline & Baseline & Follow-up & Change \\
\hline Males & & & \\
Age yrs & $41(26,59)$ & $50(34,67)$ & $8(7,10)$ \\
Weight kg & $76(59,65)$ & $77(60,100)$ & $2(-6,13)$ \\
Height cm & $171(160,183)$ & $170(159,182)$ & $-1(-4,2)$ \\
BMI kg·m & $25.69(20.92,31.54)$ & $26.78(21.68,33.81)$ & $0.96(-1.79,4.54)$ \\
Females & $41(27,60)$ & $50(35,68)$ & $8(7,10)$ \\
Age yrs & $62(49,83)$ & $64(50,87)$ & $2(-6,12)$ \\
Weight kg & $158(149,167)$ & $157(148,165)$ & $-1(-4,3)$ \\
Height cm & $24.86(19.95,34.22)$ & $26.04(20.57,35.13)$ & $1.09(-2.57,5.00)$ \\
BMI kg·m & & & \\
\hline
\end{tabular}

Data are presented as medians (5th, 95th percentiles). BMI: body mass index. ${ }^{\#}: \mathrm{n}=584 ;{ }^{\top}: \mathrm{n}=617$. 
Table 2. - Number of observations of spirometric and diffusing variables at baseline and follow-up and of their changes, separately by sex

\begin{tabular}{|c|c|c|c|c|}
\hline & Subjects $n$ & Baseline & Follow-up & Change \\
\hline \multicolumn{5}{|l|}{ Males } \\
\hline VC L & 584 & $4.85(3.58,6.45)$ & $4.74(3.37,6.29)$ & $-0.12(-0.72,0.42)$ \\
\hline FVC L & 553 & $4.74(3.50,6.28)$ & $4.63(3.27,6.16)$ & $-0.15(-0.69,0.30)$ \\
\hline FEV1 L & 553 & $3.60(2.40,4.80)$ & $3.44(2.14,4.65)$ & $-0.16(-0.63,0.20)$ \\
\hline $\mathrm{FEV}_{1} / \mathrm{VC}$ & 553 & $0.73(0.59,0.84)$ & $0.72(0.55,0.82)$ & $-0.02(-0.11,0.05)$ \\
\hline FEV $1 / F V C$ & 553 & $0.76(0.60,0.85)$ & $0.75(0.59,0.83)$ & $-0.01(-0.08,0.04)$ \\
\hline $\mathrm{DL}, \mathrm{CO} \mathrm{mL} \cdot \mathrm{min}^{-1} \cdot \mathrm{mmHg}^{-1}$ & 411 & $33.26(23.13,46.17)$ & $33.52(20.86,45.44)$ & $-0.21(-11.07,8.33)$ \\
\hline KCO $\mathrm{mL} \cdot \mathrm{min}^{-1} \cdot \mathrm{mmHg}^{-1} \cdot \mathrm{L}^{-1}$ & 411 & $4.84(3.31,6.30)$ & $4.68(2.89,6.22)$ & $-0.11(-1.73,1.10)$ \\
\hline \multicolumn{5}{|l|}{ Females } \\
\hline VC L & 617 & $3.55(2.74,4.44)$ & $3.45(2.49,4.36)$ & $-0.12(-0.57,0.29)$ \\
\hline FVC L & 578 & $3.48(2.71,4.33)$ & $3.33(2.42,4.21)$ & $-0.14(-0.60,0.20)$ \\
\hline FEV1 L & 578 & $2.70(2.01,3.42)$ & $2.49(1.72,3.24)$ & $-0.18(-0.52,0.09)$ \\
\hline $\mathrm{FEV} 1 / \mathrm{VC}$ & 578 & $0.75(0.65,0.86)$ & $0.73(0.61,0.82)$ & $-0.03(-0.12,0.05)$ \\
\hline FEV1/FVC & 578 & $0.77(0.67,0.87)$ & $0.76(0.65,0.84)$ & $-0.02(-0.10,0.05)$ \\
\hline$D \mathrm{~L}, \mathrm{CO} \mathrm{mL} \cdot \mathrm{min}^{-1} \cdot \mathrm{mmHg}^{-1}$ & 433 & $25.97(19.28,34.15)$ & $25.10(17.27,32.90)$ & $-1.05(-8.41,6.27)$ \\
\hline $\mathrm{KCO} \mathrm{mL} \cdot \mathrm{min}^{-1} \cdot \mathrm{mmHg}^{-\mathrm{P}} \cdot \mathrm{L}^{-1}$ & 433 & $4.91(3.60,6.53)$ & $4.73(3.15,6.24)$ & $-0.21(-1.76,1.10)$ \\
\hline
\end{tabular}

Data are presented as medians (5th, 95th percentiles) unless otherwise stated. VC: vital capacity; FVC: forced vital capacity; FEV1: forced expiratory volume in one second; DL,CO: carbon monoxide diffusing capacity of the lung; KCO: carbon monoxide transfer coefficient.

Table 3. - Proportion of negative changes of vital capacity (VC) $(\mathrm{dVC}<0)$, forced vital capacity $(\mathrm{FVC})(\mathrm{dFVC}<0)$ and forced expiratory volume in one second $\left(F E V_{1}\right)\left(\mathrm{dFEV}_{1<0)}\right.$ for different sex and quartiles of body mass index (BMI) changes (dBMl)

\begin{tabular}{lccccc}
\hline & \multicolumn{4}{c}{ dBMI quartiles $\mathrm{kg} \cdot \mathrm{m}^{-2}$} & Total \\
\cline { 2 - 4 } & 1st & 2nd & 3rd & 4th & \\
\hline Males & & & & & \\
dVC $<0$ & 54 & 58 & 69 & 77 & 64 \\
dFVC $<0$ & 54 & 67 & 75 & 79 & 69 \\
dFEV $1<0$ & 66 & 71 & 85 & 92 & 78 \\
Females & & & & & \\
dVC $<0$ & 62 & 68 & 71 & 67 & 67 \\
dFVC $<0$ & 75 & 69 & 75 & 77 & 74 \\
dFEV $1<0$ & 79 & 87 & 86 & 91 & 86 \\
\hline
\end{tabular}

Data presented as \%.

function changes (dVC, dFVC, and dFEV1) decreased within increasing dBMI quartiles. The trend was clearer in males than in females.

Tables 4 and 5 report the regression estimates for the final models for the five lung function and the two diffusing capacity indexes separately by sex. The only significant interaction was observed in both sexes between baseline BMI and dBMI in the model for $\mathrm{dVC}$, suggesting that baseline BMI represents an effect modifier of the relationship between dBMI and dVC. In both sexes, BMI increases $(\mathrm{dBMI}>0)$ over time caused reductions in $\mathrm{dFVC}(\mathrm{dFVC}<0)$ and dFEV1 $\left(\mathrm{dFEV}_{1}<0\right)$. For example, as shown in table 4, -20 and $-16 \mathrm{~mL}$ were the median values of dFEV1 and -3 and $-11 \mathrm{~mL}$ were those of $\mathrm{dFVC}$, corresponding to a dBMI unit change in males and females, respectively. The effect of $\mathrm{dBMI}$ on $\mathrm{dVC}$ can be seen in the models considering the joint effect of the terms dBMI and the interaction BMI*dBMI: the overall outcome is negative. This effect will be further exemplified below as a comment to figure 1. Among females, dBMI caused statistically significant decreases of $\mathrm{dFEV}_{1} / \mathrm{VC}$ and nonsignificant decreases of $\mathrm{dFEV}_{1 /}$ FVC. In contrast, in males, dBMI caused nonsignificant increases of $\mathrm{dFEV} 1 / \mathrm{VC}$ and statistically significant increases of $\mathrm{dFEV} 1 / \mathrm{FVC}$. These relationships may be explained considering that in males $\mathrm{VC}$ and FVC reductions after BMI increases were greater than reductions of FEV1, causing positive changes of the ratios. BMI increases seemed to provoke a slight positive variation in median $D \mathrm{~L}, \mathrm{CO}$, although not significant. A strong and significant association with baseline BMI was shown by $\mathrm{d} D \mathrm{~L}, \mathrm{CO}$ whereas it wasn't by $\mathrm{d} K \mathrm{CO}$. All lung function indices decreased with aging.

Although some of the risk factors considered were associated with changes of spirometric indices and $D$ L,CO, none of them appeared to be a potential confounder except for baseline BMI that remained in the final models. As an example, table 6 shows the effects on dFEV1 of the risk factors that were not included in the final regression models shown in tables 4 and 5 for males and females separately. For both sexes, low socioeconomic status and persistent smoking showed negative effects on FEV1 changes. Occupational exposure was significantly associated with FEV1 decrease in males only.

To graphically represent the effect modifications of baseline BMI values, figure 1 shows predicted values of dVC (by regression estimates in table 2) for two males and two females at 40 yrs with baseline BMI of 20 and $30 \mathrm{~kg} \cdot \mathrm{m}^{-2}$, respectively. Those who increased their BMI reduced their lung function. Males appear to have larger reductions of $\mathrm{VC}$ than females as they get fatter. For a unit increase in BMI, 40-yr-old males with 20 and $30 \mathrm{~kg} \cdot \mathrm{m}^{-2}$ of BMI at baseline lose 0.021 and $0.053 \mathrm{~L}$ of $\mathrm{VC}$, respectively. Whereas in 40-yr-old females with 20 and $30 \mathrm{~kg} \cdot \mathrm{m}^{-2}$ of BMI at baseline, a unit increase in BMI corresponds to a VC loss of 0.003 and $0.026 \mathrm{~L}$ of $\mathrm{VC}$, respectively. VC losses after 
Table 4. - Change in vital capacity (dVC), forced vital capacity (dFVC), forced expiratory volume in one second (dFEV1), $\mathrm{dFEV}_{1} / \mathrm{NC}, \mathrm{dFEV}_{1} / \mathrm{FVC}$ as functions of age at baseline, body mass index (BMI) at baseline and dBMI, separately by sex

Males

Females

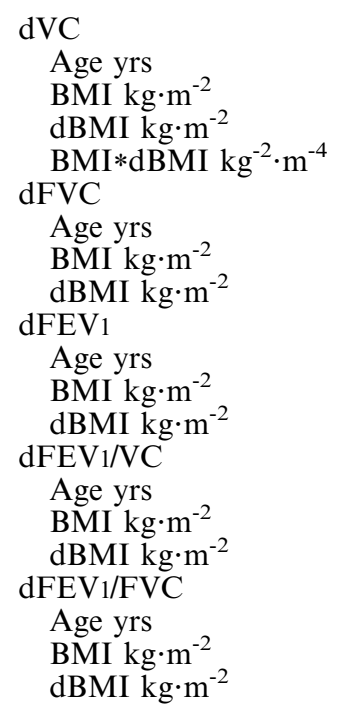

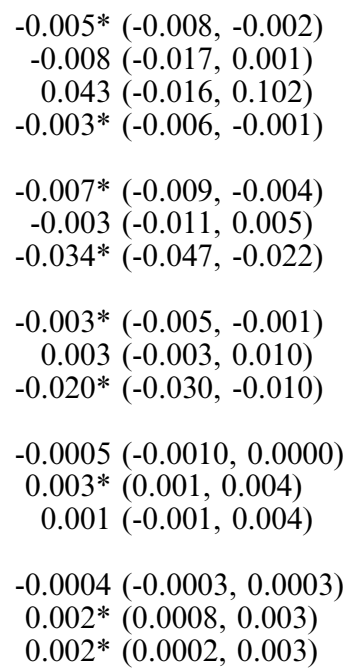

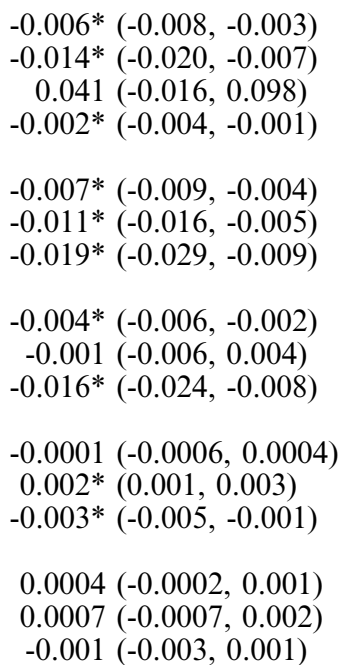

Data are presented as regression coefficient estimates ( $95 \%$ confidence intervals). $*$ : $\mathrm{p}<0.05$ significantly different from zero.

Table 5.-Changes in the carbon monoxide diffusing capacity of the lung $(\mathrm{d} D \mathrm{~L}, \mathrm{CO})$ and carbon monoxide transfer coefficient ( $\mathrm{d} K \mathrm{CO}$ ) as functions of age at baseline, body mass index (BMI) at baseline, and dBMI, separately by sex

\begin{tabular}{ccc}
\hline & Males & Females \\
\hline $\mathrm{d} D \mathrm{~L}, \mathrm{CO}$ & & \\
Age yrs & $-0.045(-0.104,0.014)$ & $-0.055(-0.113,0.004)$ \\
$\mathrm{BMI}$ & $0.285^{*}(0.082,0.481)$ & $0.058(-0.084,0.200)$ \\
$\mathrm{kg} \cdot \mathrm{m}^{-2}$ & $0.046(-0.232,0.324)$ & $0.094(-0.148,0.335)$ \\
$\mathrm{dBMI}$ & \\
$\mathrm{kg} \cdot \mathrm{m}^{-2}$ & & \\
$\mathrm{~d} \mathrm{KCO}$ & & $-0.003(-0.013,0.007)$ \\
$\mathrm{Age} \mathrm{yrs}$ & $-0.001(-0.010,0.007)$ & $0.013(-0.010,0.037)$ \\
$\mathrm{BMI}$ \\
$\mathrm{kg} \cdot \mathrm{m}^{-2}$ & $0.013(-0.015,0.041)$ & \\
$\mathrm{dBMI}$ & $0.017(-0.02,0.054)$ & $0.029(-0.011,0.069)$ \\
$\mathrm{kg} \cdot \mathrm{m}^{-2}$ & & \\
\hline
\end{tabular}

Data are presented as regression coefficient estimates $(95 \%$ confidence intervals). ${ }^{*}: \mathrm{p}<0.05$ significantly different from zero.

BMI increases are greater for more obese individuals. Intersections with the vertical axes show the median decline for those who reported no BMI changes over time $(-0.04$ and $-0.12 \mathrm{~L}$ for the males, -0.02 and $-0.16 \mathrm{~L}$ for the females with a BMI of 20 and $30 \mathrm{~kg} \cdot \mathrm{m}^{-2}$, respectively). Intersections with the horizontal axes represent the reduction of BMI needed to achieve no VC change $\left(-1.9\right.$ and $-2.2 \mathrm{~kg} \cdot \mathrm{m}^{-2}$ for the males, and -6.5 and $-6.2 \mathrm{~kg} \cdot \mathrm{m}^{-2}$ for the females with a BMI of 20 and $30 \mathrm{~kg} \cdot \mathrm{m}^{-2}$, respectively). However, predictions beyond the sample range of BMI changes, reported in table 1 , should be carefully interpreted.

Regression models were also built including changes in weight instead of changes in BMI (data
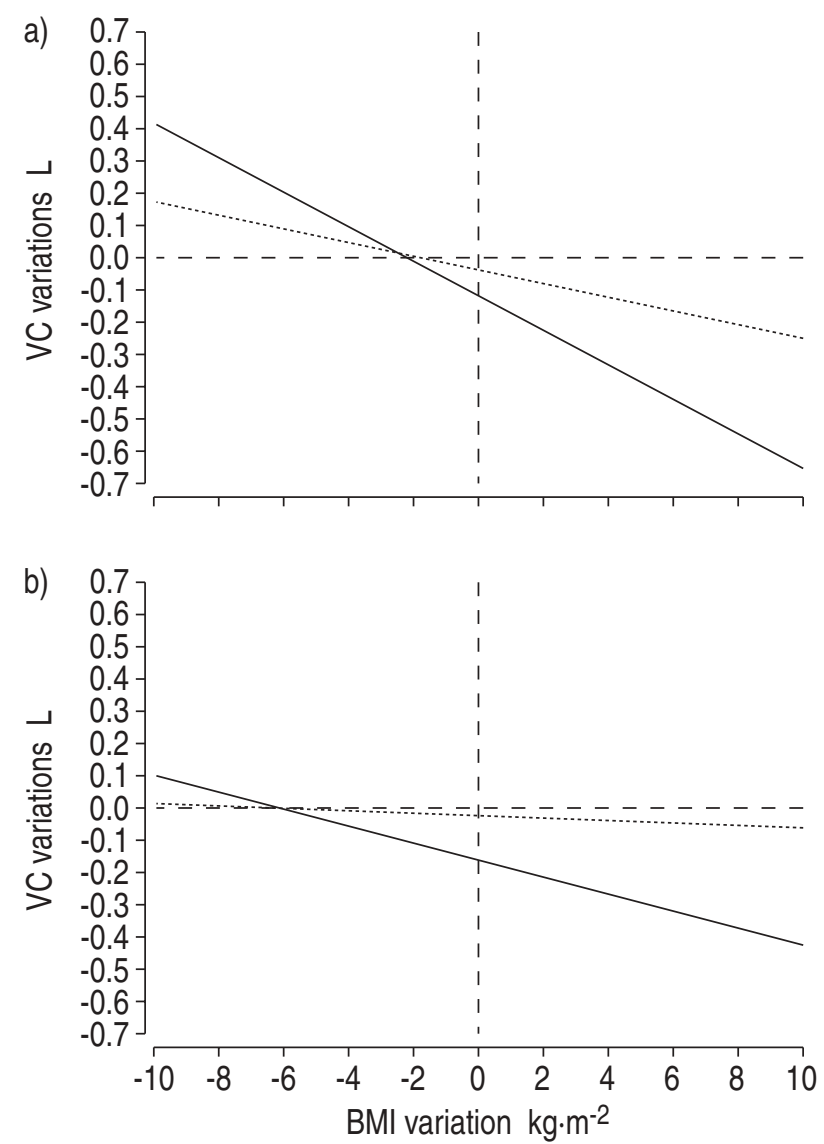

Fig. 1.-Predicted values of slow vital capacity (VC) variations against body mass index (BMI) changes in a) two male subjects and b) two female subjects at $40 \mathrm{yrs}$ of age. - : subject with a baseline BMI of $20 \mathrm{~kg} \cdot \mathrm{m}^{-2} ; \cdots \cdot$ : subject with baseline BMI of $30 \mathrm{~kg} \cdot \mathrm{m}^{-2}$. 
Table 6. - Change in forced expiratory volume in one second ( $\left.\mathrm{dFEV}_{1}\right)$, separately by sex, as a function of risk factors not included in the final regression models
Males
Females

$0.086^{*}(0.024,0.148)$
$0.091^{*}(0.033,0.148)$
$0.011(-0.044,0.066)$
$0.101^{*}(0.047,0.155)$
$0.134^{*}(0.087,0.181)$
$0.062^{*}(0.000,0.125)$
$0.082(-0.042,0.206)$
$-0.060^{*}(-0.106,-0.013)$

$0.082 *(0.019,0.145)$

$0.076 *(0.018,0.134)$

$0.049(-0.030,0.127)$

$0.056(-0.034,0.145)$

$-0.199(-0.435,0.038)$

$0.038(-0.016,0.091)$

$0.022(-0.093,0.136)$

$0.025(-0.039,0.089)$

Data are presented as regression coefficient estimates ( $95 \%$ confidence intervals). $*$ : $p<0.05$ significantly different from zero.

not reported). The models included the same covariates as in tables 3 and 4 (replacing BMI with weight). There was a significant interaction between weight changes and baseline values of height. The models based on weight changes gave predictions of lung function changes that were similar to those obtained by models based on BMI changes.

\section{Discussion}

In a general population sample of adults surveyed in northern Italy, it was observed that gains of BMI over an 8-yr follow-up time (i.e. $\mathrm{dBMI}>0$ ) induce $\mathrm{VC}$, $\mathrm{FVC}$ and FEV1 decreases (i.e. $\mathrm{dVC}<0, \mathrm{dFVC}<0$ and $\left.\mathrm{dFEV}_{1}<0\right)$. The detrimental effect of gaining weight might be reversible for many adults, as it was observed that most of those who reduced their BMI values also increased their lung function. The extent of lung function loss tends to be higher among those who, at baseline, report greater BMI values. Males appear to experience larger losses than females. Conversely, it seems that longitudinal changes of BMI cause a slight and nonsignificant increase in $D$ L,CO values in both males and females.

In order to exclude weight changes that could be related to physical growth, as usually happens in youth [25], the present authors chose to study adults aged $\geqslant 25$ yrs. In fact, in a previous study by the current authors [2], on cross-sectional and longitudinal observations from subjects 8-64 yrs old, they observed that lung function increased up to a certain value of BMI and then fell according to a parabolic trend. However, when subjects under 25 yrs were excluded, the lung function was steadily decreasing as observed in the present study.

The authors considered whether weight changes might have been a better choice than BMI changes at predicting lung function longitudinal variations. Indeed BMI changes and changes in weight were highly correlated ( $\mathrm{R}$-squared $=0.9165)$. However, the effects of weight changes on lung function were also dependent upon baseline values of height. That is the taller the subject the lesser the effect of weight changes on lung function. On the contrary, BMI changes were independent of baseline values of height. Since it was observed that selected individuals in the present study showed height changes over the follow-up time, the authors chose to use changes in BMI rather than changes in weight.

With regard to the effects of weight changes on spirometric indexes, the present results are comparable with those found by other authors both in occupational cohorts and in general population samples: CAREY et al. [7] (96 mL FEV1 loss for males and $51 \mathrm{~mL}$ for females per a $10 \mathrm{~kg}$ increase in weight over 7 yrs of follow-up, in a population-based study on adults aged 18-73 yrs); WISE et al. [6] (11.1 mL for males and $5.6 \mathrm{~mL}$ for females per a $1 \mathrm{~kg}$ increase in weight over $5 \mathrm{yrs}$, in smokers aged 30-60 yrs who had quit smoking); CHINN et al. [4] (17.6 mL per a $1 \mathrm{~kg}$ increase in weight over $\sim 7 \mathrm{yrs}$ in male shipyard workers aged 45-75 yrs). In agreement with other studies, the present authors have observed that the effect of gaining weight on decline of pulmonary function was independent of age, smoking habit, and occupational exposure [3-5, 7].

Also, in accord with the results observed in population-based studies [5-7], the present authors observed that the effect of weight gain on lung function was greater in males than in females. The results reported here support the hypothesis that this effect is likely due to sex-related differences in weight distribution. Males tend to deposit fat centrally (increasing the circumference of the abdomen), while in females the deposition is typically peripheral (increasing the circumference of the hip). Thus, a mechanical effect on the diaphragm in men, impeding expansion of lungs during inspiration, could justify their higher impairment of ventilatory function. Indeed, it has been recently observed that abdominal obesity, as measured by waist-to-hip ratio, is associated with significantly greater reductions of FVC in males compared to females and with significant reduction of FEV1 in males but not in females [26]. Since in the present sample body measurements, such as thickness of the skin-folds, girth of the abdomen, or breadth of the hips were not recorded, it was not possible to take the independent effect on lung function of different patterns of body fat deposition into account [27, 28].

In this sample it was observed that in males BMI increases over time provoked decreases in lung function that were greater for $\mathrm{VC}$ and $\mathrm{FVC}$ than for FEV1. Therefore, the ratios FEV1/VC and FEV1/FVC 
increased as BMI increased, although VC, FVC and FEV1 all decreased. In females, however, the ratio decreased mainly due to the fact that females did not report as large reductions of FVC as males.

It was also observed that the magnitude of $\mathrm{VC}$ reductions following BMI increases depended upon the baseline BMI values, whereas FVC reductions did not. In particular, the more obese at baseline the greater VC reductions over time. For 40-yr-old males with BMI values of 20 and $30, \mathrm{VC}$ reductions were 21 and $53 \mathrm{~mL}$, respectively, whereas FVC reductions were $34 \mathrm{~mL}$ for both. Such a difference could be explained considering that the slow manoeuvre is apt to yield larger volumes than the forced manoeuvre, and therefore might be more sensitive to mechanical constraints to diaphragm expansion caused by obesity.

In the final models several risk factors were not included that, although possibly significant, appeared not to confound the relationship of main interest between lung function and BMI. Among them, smoking habit is potentially modifiable over time as well as BMI. Quitting smoking compared with keeping smoking improves FEV1 change of about $11 \mathrm{~mL}$ in males and $49 \mathrm{~mL}$ in females. Conversely, reducing BMI by one unit improves FEV1 change of about $20 \mathrm{~mL}$ in males and $16 \mathrm{~mL}$ in females.

With regard to $D \mathrm{~L}, \mathrm{CO}$, far fewer papers have analysed its relationship with BMI changes, other than in small clinical samples. In a case-controlled study, higher $D$ L,CO and KCO values were found in healthy nonsmoking obese adults compared to nonobese matched controls, while the correlation analysis showed that BMI was a significant determinant for KCO [29]. In nonsmoking massively obese adults otherwise healthy, $\%$ predicted $D$ L,CO has been shown to increase with increasing obesity over the range of weight/height ratios between $0.6 \mathrm{~kg} \cdot \mathrm{cm}^{-1}$ and $1.2 \mathrm{~kg} \cdot \mathrm{cm}^{-1}$ [12]. In the same clinical sample, it was also shown that the $D \mathrm{~L}, \mathrm{CO}$ decreased after remarkable weight loss [12]. A significant correlation between BMI and DL,CO, and between BMI and KCO was found in a group of outpatients with stable COPD [10] and in a group of never smoker obese patients with moderate-to-severe obstructive sleep apnoea [11], respectively. Data from the different samples above consistently show a positive correlation between BMI and $D \mathrm{~L}, \mathrm{CO}$, which is independent from concomitant comorbidity, respiratory disease and smoking habit.

In a previous paper [9] the present authors have observed, by using a different approach of statistical analysis, that weight at baseline and change in weight were significant predictors of $D \mathrm{~L}, \mathrm{CO}$ increases over an 8 -yr period, both in adult males and females $>40$ yrs [9]. In the present paper, BMI was used instead of weight, as stated above. However, an analogous positive effect of BMI changes and BMI values at baseline (significant in males) on $D \mathrm{~L}, \mathrm{CO}$ changes in both sexes was found. For the KCO index, baseline BMI was not a significant contributor, possibly because alveolar volume, which correlated with $\mathrm{BMI}$, is already accounted for in the computation formula (i.e. $K \mathrm{CO}=D \mathrm{~L}, \mathrm{CO} / V \mathrm{~A})$.

However, the highest $D \mathrm{~L}, \mathrm{CO}$ values with weight gain have usually been observed in obese individuals. This relationship has been explained by the increased capillary blood volume in the lungs, which increases with increasing BMI $[11,12]$. In the present sample from a general population, an increase in $D \mathrm{~L}, \mathrm{CO}$ values was observed along with changes of BMI that was not statistically significant. It may be attributed to the fact that the majority of the subjects were not overweight (BMI $<25 \mathrm{~kg} \cdot \mathrm{m}^{-2}$ ) and only a few were obese (BMI $>30 \mathrm{~kg} \cdot \mathrm{m}^{-2}$ ), according to the classification of the American Society for Clinical Nutrition [30].

As mainly healthy subjects from a general population living in a rural area with low pollution were evaluated $[15,16]$, the lack of correction for haemoglobin levels should not have affected $D$ L,CO data. Indeed, it has been demonstrated that the correction for haemoglobin levels does not significantly change the uncorrected $D$ L,CO values in a large series of hospital patients in usual clinical conditions [31].

In the analyses a median regression was applied to quantify the magnitude of the effects of BMI changes on lung function variations, after adjusting for other risk factors. Assumptions for making inference by using median regression are less restrictive than those for linear regressions that are also more sensitive to outlying values (e.g. few excessively large changes).

Selecting only those with complete data may have introduced some bias into the results. As expected, those who were older and reported lesser FEV1 values at baseline were more likely to drop out. Baseline age and FEV1 mean differences between those who had complete longitudinal data (compliers) and those who had not (drop-outs) were of $\sim 3$ yrs and $126 \mathrm{~mL}$, respectively, and statistically significant. However, making the assumption that the drop-outs who were older might have had a slight increase of BMI and a large decline of FEV1, as was observed in the compliers, the bias would be in the conservative direction.

The results presented here from a large general population sample point out that the increase in body mass index value leads to a worsening of ventilatory function, especially in males. Furthermore, it was observed that most subjects who reduced their body mass index values also improved their ventilatory function. Therefore, in agreement with the study of MORGAN and REGER [32] on male workers, the current authors hypothesise that the detrimental effect of gaining weight might be reversible. This may have important clinical implications, as, for instance, overweight patients with ventilatory impairment could be routinely encouraged to lose weight to improve their lung function.

\section{Appendix}

\section{Median regression}

In usual linear regression, the expected (mean) value of the dependent variable $(\mathrm{Y})$ is a linear function of a set of covariates $(\mathrm{X})$ :

$$
\text { Mean }(\mathrm{Y} \mid \mathrm{X})=\mathrm{X} \beta
$$

where $\beta$ is the coefficient vector to be estimated. 
Regression coefficients are estimated by minimising the sum of the squared residuals, which are the differences between the observed values $Y$ and expected values $\mathrm{X} \beta$ (least-squares estimates). To obtain estimates for coefficients and standard errors normality and heteroschedasticity of the distributions of the residuals is usually assumed.

Instead in the median linear regression, the median value of the dependent variable is a linear function of a set of covariates:
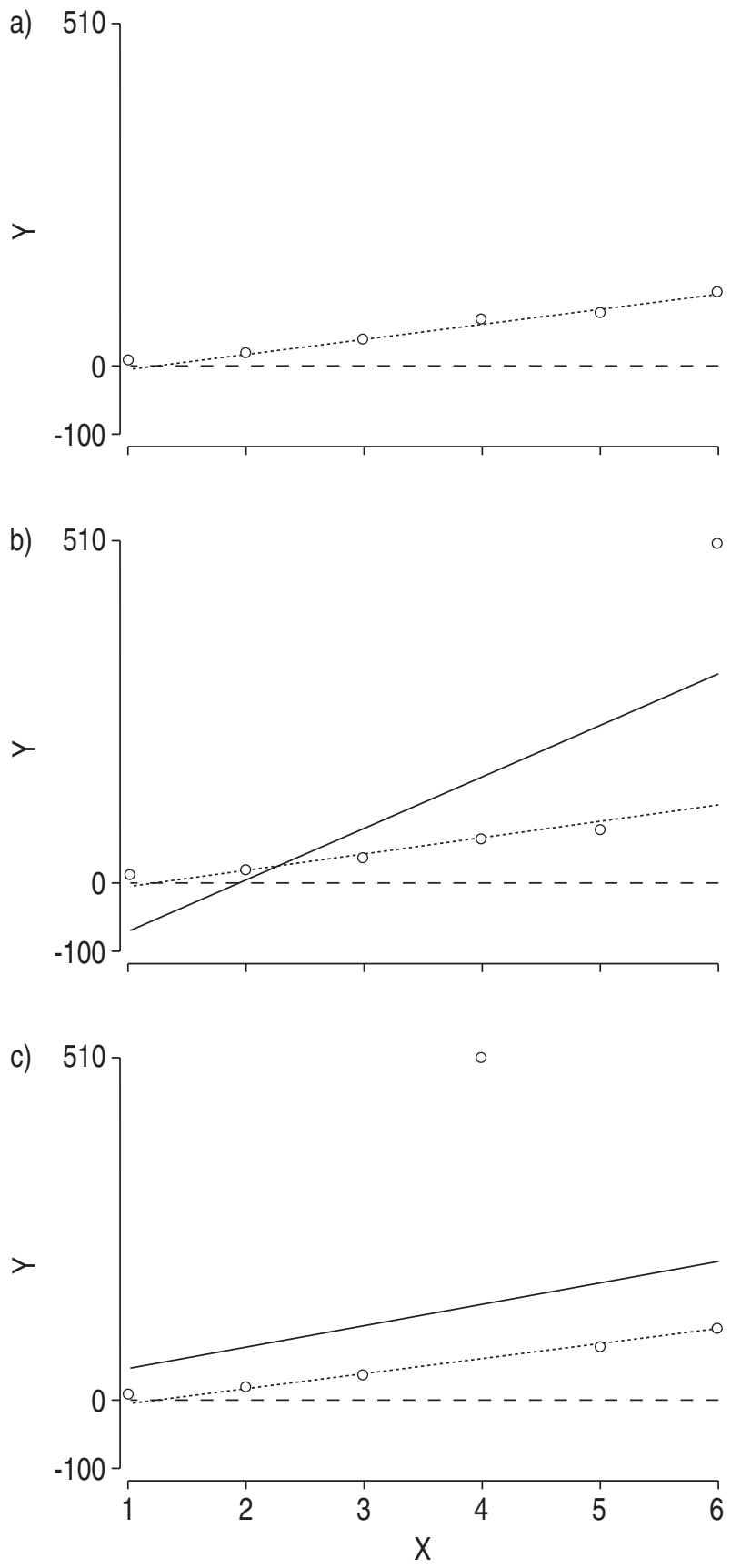

Fig. 2.-Six supposed observations (scatter dots), the median regression line $(\cdots)$ and the least-squares regression line $(-)$; panels b) and c) show how the regression lines are affected by the presence of an outlier in two possible scenarios.

$$
\operatorname{Median}(\mathrm{Y} \mid \mathrm{X})=\mathrm{X} \beta
$$

Coefficients are estimated by minimising the sum of the absolute values of the residuals ( $\mathrm{L}-1$ estimates). In order to obtain estimates and standard errors assumptions do not have to be made as for usual regression. Indeed no parametric assumption is required. The estimates for the standard errors are obtained according to the asymptotic methods proposed by KoEnKer and BASSETT [33]. The estimates of the standard errors were also validated by bootstrap sampling procedures [34].

\section{An example}

The current authors present a simple example to show what is stated in the Methods section, that median regression techniques provide answers similar to the least-squares regression when the data are linear with normally distributed errors, but differ significantly from the least-squares fit when the errors do not satisfy the normality conditions or when the data contain significant outliers. Suppose there are six observations taken on two random variables $(\mathrm{X}, \mathrm{Y})$ as follows: $(1,10),(2,20),(3,40)$, $(4,70),(5,80),(6,110)$. In figure $2 a)$, the six observations (scatter dots), the median regression line $(\cdots)$ and the least-squares regression line $(-)$ are shown. The two regression lines overlap (thus the latter is not visible in the figure), meaning that leastsquares and median regressions give very similar answers. Figure 2b) and c) show how the regression lines are affected by the presence of an outlier in two possible scenarios.

Suppose that the last observation was mistakenly recorded as $(6,510)$ instead of the correct $(6,110)$. The median regression is almost the same as in panel a), as if the data were correctly recorded, whereas the leastsquares regression is highly changed by the presence of the outlier. Figure 2c) is similar to panel b), except that the fourth observation was mistakenly recorded as $(4,510)$ instead of the correct $(4,70)$. Again the least-squares regression line is highly affected by the presence of an outlier whereas the median regression is not.

Acknowledgements. The authors wish to thank the "Scientific Committee of the Porto Tolle Power Plant" and the following individuals who made it possible to plan and implement the study: L. Ballerin, P. Biavati, T. Sapigni, M. Simoni (University of Ferrara); G. Baiocchi, E. Cestari, G. Nardini, R. Polato, M. Saetta, R. Zambon (University of Padova), E. Diviggiano, P. Fazzi, C. Giuntini, P. Modena, P. Paoletti, G. Pistelli, D. Talini, M. Vellutini (University of Pisa), the nurses of USL No. 31 (G. Gambato, D. Smorgon, S. Cavazzin, A. Pavan, M. Zambello, S. Zago) and USL No. 33 (L. Mari). The authors also thank the hundreds of residents of the Delta del Po area who participated in the study. 


\section{References}

1. Hankinson JL, Odencrantz JR, Fedan KB. Spirometric reference values from a sample of the general U.S. population. Am J Respir Crit Care Med 1999; 159: 179-187.

2. Pistelli F, Bottai M, Viegi G, et al. Smooth reference equations for slow vital capacity and flow-volume curve indexes. Am J Respir Care Med 2000; 161: 899 905.

3. Wang M-L, McCabe L, Hankinson JL, et al. Longitudinal and cross-sectional analyses of lung function in steelworkers. Am J Respir Crit Care Med 1996; 153: 1907-1913.

4. Chinn DJ, Cotes JE, Reed JW. Longitudinal effects of change in body mass on measurements of ventilatory capacity. Thorax 1996; 51: 699-704.

5. Chen Y, Horne SL, Dosman JA. Body weight and weight gain related to pulmonary function decline in adults: a six year follow up study. Thorax 1993; 48: 375-380

6. Wise RA, Enright PL, Connett JE, et al. Effect of weight gain on pulmonary function after smoking cessation in the Lung Health Study. Am J Respir Crit Care Med 1998; 157: 866-872.

7. Carey IM, Cook DG, Strachan DP. The effects of adiposity and weight change on forced expiratory volume decline in a longitudinal study of adults. Int J Obes Relat Metab Disord 1999; 23: 979-985.

8. Sherrill DL, Enright PL, Kaltenborn WT, Lebowitz MD. Predictors of longitudinal changes in diffusing capacity over 8 years. Am J Respir Crit Care Med 1999; 160: 1883-1887.

9. Viegi G, Sherrill DL, Carrozzi L, et al. An 8-years follow-up of $\mathrm{CO}$ diffusing capacity in a general population sample of North Italy. Chest 2001; 120: 74-80.

10. Sahebjami H, Doers JT, Render ML, Bond TL. Anthropometric and pulmonary function test profiles of outpatients with stable chronic obstructive pulmonary disease. Am J Med 1993; 94: 469-474.

11. Collard P, Wilputte JY, Aubert G, Rodenstein DO, Frans A. The single-breath diffusing capacity for carbon monoxide in obstructive sleep apnea and obesity. Chest 1996; 110: 1189-1193.

12. Ray CS, Sue DY, Bray G, Hansen JE, Wasserman K. Effects of obesity on respiratory function. Am Rev Respir Dis 1983; 128: 501-506.

13. Paoletti P, Carrozzi L, Viegi G, et al. Distribution of bronchial responsiveness in a general population: effect of sex, age, smoking, and level of pulmonary function. Am J Respir Crit Care Med 1995; 151: 1770 1777.

14. Carrozzi L, Giuliano G, Viegi G, et al. The Po River Delta epidemiological study of obstructive lung disease: sampling methods, environmental and population characteristics. Eur J Epidemiol 1990; 6: 191200.

15. Viegi G, Paoletti P, Prediletto R, et al. Prevalence of respiratory symptoms in an unpolluted area of northern Italy. Eur Respir $J$ 1988; 1: 311-318.

16. Viegi G, Pedreschi M, Baldacci S, et al. Prevalence rates of respiratory symptoms and diseases in general population samples of North and Central Italy. Int J Tuberc Lung Dis 1999; 3: 1034-1042.

17. Viegi G, Carrozzi L, Di Pede F, et al. Risk factors for chronic obstructive pulmonary disease in a North Italian rural area. Eur J Epidemiol 1994; 10: 725-731.

18. Paoletti P, Prediletto R, Carrozzi L, et al. Effects of childhood and adolescence-adulthood respiratory infections in a general population. Eur Respir $J$ 1989; 2: 428-436.

19. Paoletti P, Viegi G, Pistelli G, et al. Reference equations for the single breath diffusing capacity. A cross sectional analysis and effect of body size and age. Am Rev Respir Dis 1985; 132: 806-813.

20. Paoletti P, Pistelli F, Fazzi P, et al. Reference values for vital capacity and flow-volume curves from a general population study. Bull Eur Physiopathol Respir 1986; 22: 451-456.

21. Ferris BG. Epidemiology standardization project. Am Rev Respir Dis 1978; 118: 255-288.

22. Pistelli G, Carmignani G, Paoletti P, et al. Comparison of algorithms for determining the end-point of the forced vital capacity manoeuvre. Chest 1987; 91 : 100-105.

23. Ogilvie CM, Forster RE, Blakemore WS, Morton JW. A standardized breath holding technique for the clinical measurement of the diffusing capacity of the lung for carbon monoxide. J Clin Invest 1957; 36: $1-17$.

24. Narula SC, Saldiva PH, Andre CD, Elian SN, Ferreira AF, Capelozzi V. The minimum sum of absolute errors regression: a robust alternative to the least squares regression. Stat Med 1999; 18: 1401-1417.

25. Schoenberg JB, Beck GJ, Bouhuys A. Growth and decay pulmonary function in healthy blacks and whites. Respir Physiol 1978; 33: 367-393.

26. Harik-Khan RI, Wise RA, Fleg JL. The effect of gender on the relationship between body fat distribution and lung function. J Clin Epidemiol 2001; 54: 399-406.

27. Lazarus R, Sparrow D, Weiss ST. Effects of obesity and fat distribution on ventilatory function. Chest 1997; 111: 891-898.

28. Collins LC, Hoberty PD, Walker JF, Fletcher EC, Peiris AN. The effect of body fat distribution on pulmonary function tests. Chest 1995; 107: 1298-1302.

29. Rubinstein I, Zamel N, DuBarry L, Hoffstein V. Airflow limitation in morbidly obese, nonsmoking men. Ann Intern Med 1990; 112: 828-832.

30. American Society for Clinical Nutrition. Energy, obesity, and body weight standards. (Panel summary statement). Am J Clin Nutr 1987; 45: 1035-1047.

31. Viegi G, Baldi S, Begliomini E, Ferdeghini EM, Pistelli F. Single breath diffusing capacity for carbon monoxide: effects of adjustment for inspired volume dead space, carbon dioxide, hemoglobin and carboxyhemoglobin. Respiration 1998; 65: 56-62.

32. Morgan WKC, Reger RB. Rise and fall of the FEV1. Chest 2000; 118: 1639-1644.

33. Koenker R, Bassett G Jr. Robust tests for heteroschedasticity based on regression quantiles. Econometrica 1982; 50: 43-61.

34. Efron B, Tibshirani R. Bootstrap methods for standard errors, confidence intervals and other measures of statistical accuracy. Statistical Science 1986; 1: 54-75. 